\title{
Circulación de efectos de Castilla entre Maracaibo y la provincia de Pamplona (1785-1819)
}

Circulation of Imported Assets between Maracaibo and Pamplona (I785-I8I9)

DOI: https://I0.22380/20274688.843

\begin{tabular}{c}
\hline Recibido: 17 de julio del 2019 \\
\hline Aprobado: 21 de septiembre del 2019 \\
\hline
\end{tabular}

JASON ANDRÉS BEDOLLA*

Universidad Nacional de Colombia, sede Bogotá jbedolla@unal.edu.co

\section{R E S U M E N}

El objetivo de este artículo es comprender independencia de la Nueva Granada. Para la circulación de efectos importados, a la elaboración del trabajo se usaron los litravés del puerto de Maracaibo, hacia la bros de cuentas de alcabala de Pamplona, al provincia de Pamplona entre 1785 y 1819 . igual que las guías de comercio elaboradas Se observa cómo este tráfico aumentó a por los funcionarios del puerto venezolaprincipios del siglo xIX y se vio perjudi- no, todo ubicado en el Archivo General de cado posteriormente por el proceso de la Nación, sección Archivo Anexo II y III.

Palabras clave: efectos de Castilla, comercio, flujos de mercancías

* Historiador de la Universidad Industrial de Santander, estudiante de maestría en Historia de la Universidad Nacional de Colombia, sede Bogotá. Interés en historia económica y circulación de bienes en el nororiente neogranadino en los siglos XVIII y XIX. Miembro del grupo de Historia Económica y Social de la Universidad Nacional de Colombia. 


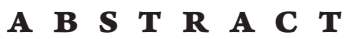

The main objective of this paper is to understand the commercial exchange of imported assets between Maracaibo's port and the province of Pamplona from 1785 to 1819. It regards how the traffic increased in the early $19^{\text {th }}$ century and was later affected by the independence of New Granada. This article uses the libros de cuentas de alcabala from Pamplona and guías de comercio made by the port functionaries stored in Archivo General de la Nación, sección Archivo Anexo II and III.

Keywords: efectos de Castilla, trade, freight flows

\section{Introducción: movilidad entre la provincia de Pamplona y el espacio marabino}

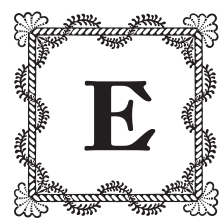

$\mathrm{n}$ años recientes, los estudios acerca de la movilidad comercial a fines del siglo XVIII han ido aumentando en la historiografía colombiana. Las nuevas investigaciones han modificado la visión general acerca de la circulación de bienes en el virreinato de la Nueva Granada, de manera que se ha reemplazado la idea de regiones con economías casi autárquicas por la de un espacio económico mucho más integrado.

Gran parte de estos nuevos estudios han recibido la influencia de las investigaciones de Carlos Sempat Assadourian, al igual que de un nuevo análisis de los documentos fiscales y las guías comerciales que ha permitido a las más recientes generaciones de historiadores económicos ${ }^{\mathrm{I}}$ proponer una mayor integración comercial neogranadina. Sin embargo, son escasos los trabajos que han tendido a observar las conexiones comerciales entre el nororiente neogranadino y la región occidental venezolana.

La región histórica marabina configuró su comercio alrededor de la explotación agropecuaria, facilitada por la capacidad de comunicación que brindaban el lago de Maracaibo y sus ríos afluentes con el oriente neogranadino y el interior de la capitanía de Venezuela (Cardozo).

El golfo de Maracaibo y su lago interior, bañado hídricamente por la afluencia de los diferentes ríos que nacen en el interior de la capitanía de Venezuela

I Véanse, por ejemplo, los trabajos de Moreno, Muñoz Torres, Bohórquez o Pinto. 
y en el nororiente neogranadino, contrasta fuertemente con el alto relieve del nororiente del virreinato. La movilidad entre ambos espacios implicó un reto constante para los habitantes indígenas del periodo prehispánico, pero también para los pobladores y comerciantes españoles que se asentaron en la región del golfo y en las montañas neogranadinas.

El alto relieve que conformaba a la provincia de Pamplona, en la desarticulación de la cordillera oriental de los Andes, albergaba un grupo de valles que conectaban con la provincia de Maracaibo, a través de los cuales podía internarse desde Venezuela hacia el interior de la Nueva Granada.

La mayoría de las fundaciones en la parte oriental de la provincia nacen así como proyecto del Cabildo de Pamplona para facilitar la movilización entre la ciudad y la región del valle de Mérida, al igual que reducir a los diferentes pueblos indígenas tachiríes (Guerrero et al. 19). Estas erecciones permitieron un control de los ríos Zulia, Pamplona y Táchira, así como de los puntos de movilidad entre la cordillera Oriental neogranadina y el espacio marabino.

La apertura a través de la ruta del valle de Cúcuta permitió el establecimiento de diferentes parroquias y pueblos de indios durante los siglos XVII y XVIII que ganarían una mayor importancia dentro del comercio internacional gracias a la exportación de cacao neogranadino hacia el puerto de Veracruz, México (Guerrero 355). Las villas de San José y del Rosario de los valles de Cúcuta nacieron por la necesidad de conectar el sur de Mérida (San Cristóbal, La Grita, Lobatera, San Antonio) con el área nororiental neogranadina, lo que aseguraba un paso entre Maracaibo y el interior neogranadino para la circulación, principalmente, de bienes de la tierra (Urdanet 253).

La importancia del paso sería tal que a principios del siglo xix Francisco José de Caldas, al hablar de la provincia de Pamplona, anotaba:

El ramo oriental de la cordillera de los Andes ocupa casi toda esta provincia, formando distintos valles, y dejando libre la comunicación de los lugares situados al oriente con la costa del mar del norte por medio del río Zulia, que incorporándose con el Catatumbo, que viene de Ocaña entra en la Laguna de Maracaibo. (Caldas I-2)

La circulación entre el golfo de Maracaibo y el nororiente neogranadino ha sido poco estudiada por la historiografía colombiana. Las escasas investigaciones, principalmente realizadas por venezolanos, se han centrado en la producción de café y cacao en los valles de Cúcuta y su conexión a través del lago (Cardozo). 
El objetivo de esta investigación es comprender cómo se dio la circulación de efectos de Castilla entre el puerto de Maracaibo y la provincia de Pamplona durante las primeras décadas del siglo Xix y cómo se vio afectada por el proceso de independencia de la Nueva Granada. Se busca así observar el puerto como una zona de entrada de géneros importados que suplió al virreinato y formó una vía alternativa a los productos importados desde Cartagena durante las primeras décadas del siglo xix.

Para la realización del trabajo fue necesario utilizar dos tipos de fuentes. Por una parte, se recopilaron las diferentes guías de comercio producidas en el puerto de Maracaibo con destino a la Nueva Granada, las cuales se hallan en el Archivo Anexo II, sección Real Hacienda Cuentas. En segundo lugar, los libros mayores y de cargo y data de la provincia de Pamplona, que se encuentran dispersos en diferentes secciones del Archivo Anexo II y III.

Las series creadas a partir de estas fuentes presentan vacíos significativos debido a que no se conserva la totalidad de los libros fiscales. Asimismo, las guías de comercio se encuentran incompletas puesto que a Bogotá solo fueron remitidos los documentos anexados a los libros de alcabala requeridos por la administración central, que muestran solo una fracción de lo que representó el comercio entre Maracaibo y Pamplona. Sin embargo, a pesar de estos problemas, los datos son una muestra que permite ante todo observar la circulación y las fluctuaciones de este circuito a fines del siglo XVIII y principios del XIX.

\section{Circulación de géneros de Castilla}

Las importaciones de géneros manufacturados fueron un elemento en constante crecimiento dentro de la economía de las colonias americanas a fines del siglo XviII. La instauración del Reglamento de Libre Comercio en 1778 y la apertura de los puertos a las embarcaciones neutrales en 178I permitieron la movilidad de navíos de diferentes naciones. Esto, junto al rompimiento del monopolio de Cádiz, diversificó la cantidad de géneros que llegaron a las costas americanas (Mcfarlane $7 \mathrm{I}$ ).

Durante las últimas décadas del siglo XviII y la primera del XIX, los periodos de paz y guerra entre Espańa y Gran Bretaña determinaron, en ciertos momentos, la circulación de navíos entre la metrópolis y América. Durante el periodo de paz de 1783 a I795 entre ambas coronas, la península ibérica mantuvo un comercio constante con la Nueva Granada gracias a la ausencia de ataques 
por parte de la flota británica, que, en ciertas ocasiones, escoltó navíos desde las costas de Cartagena a Jamaica y Europa (De la Pedraja 219).

A diferencia del periodo de paz, la guerra que se libró entre 1796 y I80I implicó un decaimiento de la circulación entre España y la Nueva Granada. Si bien no existió una completa interrupción del flujo de bienes entre la metrópolis y los puertos neogranadinos en esos años, el número de navíos provenientes de España disminuyó significativamente ${ }^{2}$. Por el contrario, el consumo de géneros en la capital del virreinato continuó en aumento, gracias a la apertura de puertos a las "naciones neutrales". Y también gracias al contrabando (Moreno 220).

El último cuarto del siglo XviII fue un periodo de aumento sobre la presión fiscal en todo el virreinato, el cual se vio beneficiado del crecimiento demográfico que estimuló el comercio regional tanto de bienes importados como de la tierra (Meisel 77). El aprovisionamiento de géneros de Castilla en la provincia de Pamplona durante el periodo 1780-I819 sería la expresión de un cambio en las dinámicas comerciales de la ciudad. Por este cambio, el comercio con el puerto de Maracaibo remplazaría a las importaciones realizadas desde Cartagena.

Los libros de cargo y data del impuesto de alcabala aportan los datos más precisos sobre el comercio legal de los efectos de Castilla con que se cuenta, para poder comprender cómo varió el comercio de los bienes importados al final del periodo colonial. El cobro fiscal sobre esta clase de géneros se realizaba sobre dos ramos del impuesto: el de géneros de Castilla, que se cobraba sobre las ventas hechas por vecinos de la ciudad de Pamplona, y el ramo de tienda de mercaderías, que se tasaba sobre los diferentes géneros vendidos exclusivamente en las tiendas de la ciudad.

La curva del recaudo del ramo de géneros de Castilla mostrada en la figura I presenta tres facetas: un descenso entre 1785 y 1789 , un pequeño auge entre 1790 y 1805 , y un declive posterior hasta llegar al año de 1819. Las dos primeras etapas se caracterizan por la preponderancia de los registros de importación procedentes de Cartagena y Santafé a través del puerto de Ocaña y la poca participación de los géneros internados desde Maracaibo.

2 René De la Pedraja especifica que entre 1797 y i80 i arribaron, solo a la costa de Cartagena, nueve embarcaciones procedentes de España cuyos bienes no superaban los 80.000 pesos anuales. Asimismo, el autor menciona que esta guerra no solo significó la caída del comercio entre la metrópolis y la Nueva Granada, sino el establecimiento de una ruta de contrabando promovida por los ingleses para internar mercancías al virreinato (220). 


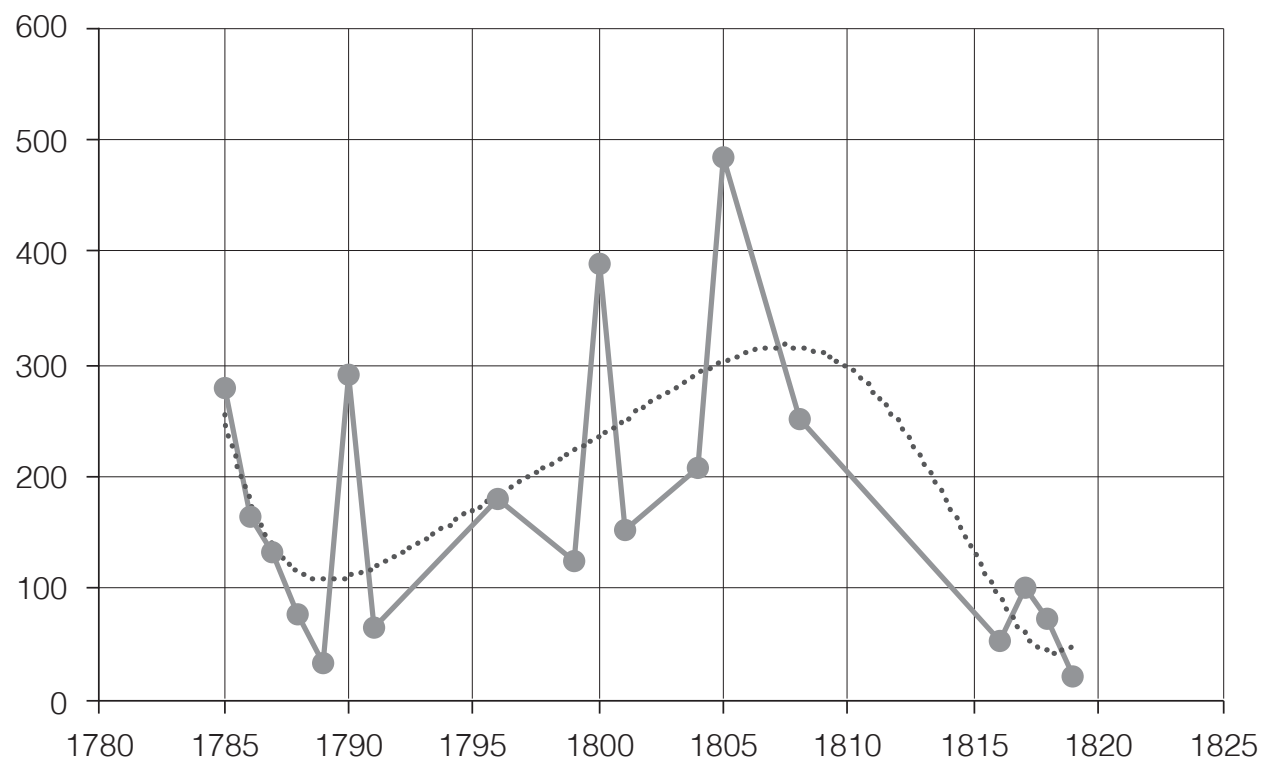

$\rightarrow$ FIGURA I.

Recaudo de la alcabala géneros de Castilla en Pamplona, I784-I8I9 ${ }^{3}$

Fuente: elaboración propia con base en AGN, (C) 3, IO, 27, 3I, 57, 75 y I77; (L).

La escasa cantidad antes de 1800 se debe a limitaciones propias del virreinato para la introducción de estos bienes a través del puerto venezolano. A pesar de que se habían aprobado las leyes de libre comercio, la entrada de bienes a través de Venezuela a la Nueva Granada estaba prohibida. En 1783 el virrey Antonio Caballero y Góngora respondió al Tribunal de Cuentas con respecto a la solicitud de Francisco Agreda Rubio, comerciante que pretendía llevar géneros importados desde Maracaibo a las villas de Socorro y San Gil, que no se permitía la entrada de los bienes, ya que los permisos a su jurisdicción eran limitados y ello podía perjudicar el comercio; asimismo, que "al exemplar de comercio libre es de puerto a puerto, y no se ha concedido interior por tierra" (AGN, $A$, 8, ff. 706 r.-706 v.)

3 El ramo de géneros de Castilla tasaba un impuesto fijo sobre las ventas de productos importados realizadas en Pamplona. El cobro se hacía sobre la cantidad de bienes vendidos en pesos dentro de la ciudad. Trabajos como los de Assadourian y Palomeque han utilizado el impuesto recaudado como un representante del comercio a través del cual pueden llegar a extrapolar, hasta cierta medida, el comercio legal de géneros importados (Assadourian y Palomeque). Asimismo, James Vladimir Torres ha revisado a profundidad el mismo ramo para la provincia de Popayán, a fin de observar el comercio de telas importadas en esa región (Torres, Entre el oro I24). 
Había un claro interés por parte del virrey de mantener a Maracaibo al margen del comercio neogranadino y preservar el monopolio de las importaciones a través de Cartagena. Las restricciones al comercio entre la región de Maracaibo y la provincia de Pamplona tuvieron objeciones de los comerciantes de Maracaibo, que veían en las trabas puestas por Caballero y Góngora una violación al Reglamento de Libre Comercio. En 1783, don José Antonio de Barrera, vecino de Maracaibo y representante de Francisco Agreda Rubio, se quejaba de las restricciones puestas por el virrey, argumentando que tanto el Reglamento de Libre Comercio como el intendente de Caracas declaraban que los diferentes frutos y efectos de Europa podían conducirse entre diferentes provincias por mar y tierra, siempre que se llevaran las correspondientes guías y se pagaran los impuestos requeridos (AGN, $A, 8$, ff. 726 r.- -726 v.)

Como se puede apreciar en la tabla I, la tendencia entre 1784 y 1789 demuestra que la prohibición virreinal redujo considerablemente la cantidad de bienes transados en la provincia. Esto se reafirma al comparar las cantidades pagadas por el ramo de efectos de Castilla con las del de tienda de mercaderes, más fluctuante en este primer periodo.

La circulación de bienes de Castilla desde Cartagena y Santafé hacia la región nororiental de la Nueva Granada se debe al papel que tuvieron estas ciudades como centros de redistribución de bienes a fines del siglo xvirI. La capital virreinal articulaba los flujos comerciales de diferentes regiones y abastecía a las zonas mineras y a las de producción agrícola de recursos importados y de aquellos del país (Muñoz y Torres 194).

El comercio de ambas ciudades con los comerciantes de Pamplona permitió que se construyeran redes sociales ${ }^{4}$ mediante parentesco o intereses comunes, a través de las cuales se abastecía de efectos importados al nororiente neogranadino. La red de don José María Villamizar, vecino de Pamplona, quien en los años de I79I y 1794 reportó al ramo de tienda de mercaderías la venta de I.925 pesos en efectos de Castilla, surgió de los negocios hechos por su padre en el

4 Se entiende por este concepto los lazos de vinculación construidos a partir de intereses comunes y vínculos personales con valor estructurante, que no se limitan a relaciones de clase ni de vecindad (Imizcoz 2I). Las redes sociales desempeñaron un papel esencial en la conformación de negocios y acuerdos comerciales en las economías del Antiguo Régimen, pues los acuerdos de reciprocidad comercial entre diferentes agentes mercantiles y tanto su cumplimiento como su reproducción dependieron de factores sociales como la lealtad y los lazos familiares. Los contratos implícitos en las transacciones se establecen dentro de lazos sociales considerados como un sistema de derechos y obligaciones (Moutoukias). 
puerto de Cartagena, quien remitía a su hijo en la ciudad de Pamplona para la venta de los efectos (AGN, $C$, I77).

$\rightarrow$ TABLA I.

Comparación ramo de efectos de Castilla y de mercaderes, I784-18195

\begin{tabular}{|c|c|c|c|c|c|}
\hline Año & $\begin{array}{c}\text { Recaudo } \\
\text { géneros de } \\
\text { Castilla en } \\
\text { pesos }\end{array}$ & $\begin{array}{c}\text { Recaudo ramo } \\
\text { de mercaderes } \\
\text { en pesos }\end{array}$ & Año & $\begin{array}{c}\text { Recaudo } \\
\text { géneros de } \\
\text { Castilla en } \\
\text { pesos }\end{array}$ & $\begin{array}{l}\text { Recaudo ramo } \\
\text { de mercaderes } \\
\text { en pesos }\end{array}$ \\
\hline 1784 & 179,3125 & 8 & I8OI & 150,625 & 116,15625 \\
\hline 1786 & 162,5 & 77,53125 & 1803 & & 159,625 \\
\hline 1787 & 132,21875 & 17 & I804 & 206,78125 & \\
\hline 1788 & 78 & 274,625 & 1805 & 483,90625 & $\mathrm{I}, \mathrm{I} 875$ \\
\hline 1789 & 32,8125 & 17 & 1806 & 206,71875 & 35,375 \\
\hline 1790 & 292,3125 & 101,90625 & I808 & 249,625 & 35,5 \\
\hline I79I & 64,96875 & I23 & 1809 & & \\
\hline 1794 & 56 & 32,90625 & I8I6 & 53,6875 & \\
\hline 1796 & 179,3125 & 463,75 & I8I7 & IOI, 46875 & \\
\hline 1799 & 125,25 & 71,03125 & I 8I 8 & 71,3125 & \\
\hline 1800 & 388,8 I 25 & 439,625 & I819 & 23,1875 & \\
\hline
\end{tabular}

Fuente: elaboración del autor con base en AGN (C) 3, IO, 27, 3I, 57, 75, I77; (L).

Por otro lado, la red de comercio de efectos de Castilla pudo conectarse a través de las redes de circulación de cacao entre los miembros de comercio de Pamplona y Santafé. Don Diego Martín de Peralta, vecino de Pamplona, vendió en el año I806, 364 pesos en géneros traídos desde Santafé, lugar donde

5 Recaudo del ramo de efectos de Castilla y ramo de tienda de mercaderes de la ciudad de Pamplona. Para facilitar los cálculos se pasaron los reales a base ıo, donde un real equivale a 0,125 pesos y 8 reales a un peso. 
vendía cacao a don Pedro Rodríguez de La Serna y a don Manuel Fuenmayor (AGN, $A A, \mathrm{I} 3$; $C 3$, ff. 82 r.-86 r.).

La segunda fase muestra un cambio en la tendencia de la curva de la figura I, a partir de I790. En I793, durante el gobierno del virrey José Manuel de Ezpeleta, la situación cambiaría pues se permitió la entrada de bienes extranjeros a la provincia de Pamplona a través del puerto de Maracaibo. La principal condición para la internación de géneros fue el pago del $5 \%$ de alcabala (AGN, $A$, I8, ff. 29 r.-30 r.). Sin embargo, entre 1793 y I800, a los efectos provenientes de los valles de Cúcuta se les siguió cobrando el $2 \%$. No fue sino hasta I 800 que comenzó a cobrarse en la ciudad de Pamplona el requerido $5 \%$, de modo que se ejercían dos aranceles diferentes dependiendo de la procedencia de los géneros.

Durante este lapso, los efectos importados desde el puerto de Maracaibo, y sobre todo los remitidos desde las villas de San José y del Rosario de Cúcuta, comienzan a tener gran relevancia. La figura 2 muestra la procedencia de todos los registros realizados en la ciudad entre 1784 y $1819^{6}$. A partir 1798 , la cantidad de registros provenientes de Cartagena comienza a disminuir, mientras que los de Maracaibo alcanzan una mayor importancia en los registros fiscales, que permanecerá hasta I8I9.

Los datos aportados por Nathalie Moreno Rivera sobre el recaudo realizado en la ciudad de Santafé después de I8oo son de constante crecimiento en el caso del impuesto de géneros importados. En Tunja, a pesar de oscilar entre I80I y I802, el recaudo de efectos de Castilla fue ascendente (Moreno).

El ingreso fiscal de la rama de efectos de Castilla de la ciudad de Pamplona no fue tan preponderante como en otras regiones de la Nueva Granada. Entre I789 y i819 el recaudo no superaba el io \% del total de la alcabala, mientras en la capital del virreinato los géneros importados fueron el 49,4\% del ingreso fiscal (Muñoz y Torres i79).

Los montos en pesos por esta clase de bienes no se comparaban tampoco con las provincias circundantes, como Girón o la villa del Socorro. En I8I7, mientras Pamplona registra con la suma de ambos ramos ior pesos, 3 reales y 3 cuartillos, el ingreso en la administración de Girón fue de 663 pesos con

6 En la figura I, los registros del ramo de bienes de Castilla son un indicador útil para observar la procedencia de los géneros que fueron vendidos de forma legal en la ciudad entre i 784 y I819. Dichos registros no pueden confundirse con la cantidad de bienes ingresados, ya que los libros de cargo y data solo registraban el cobro del impuesto sobre los bienes y la ciudad o puerto de procedencia de ellos. La única forma de ver los diferentes bienes ingresados es a través de las guías de comercio. 


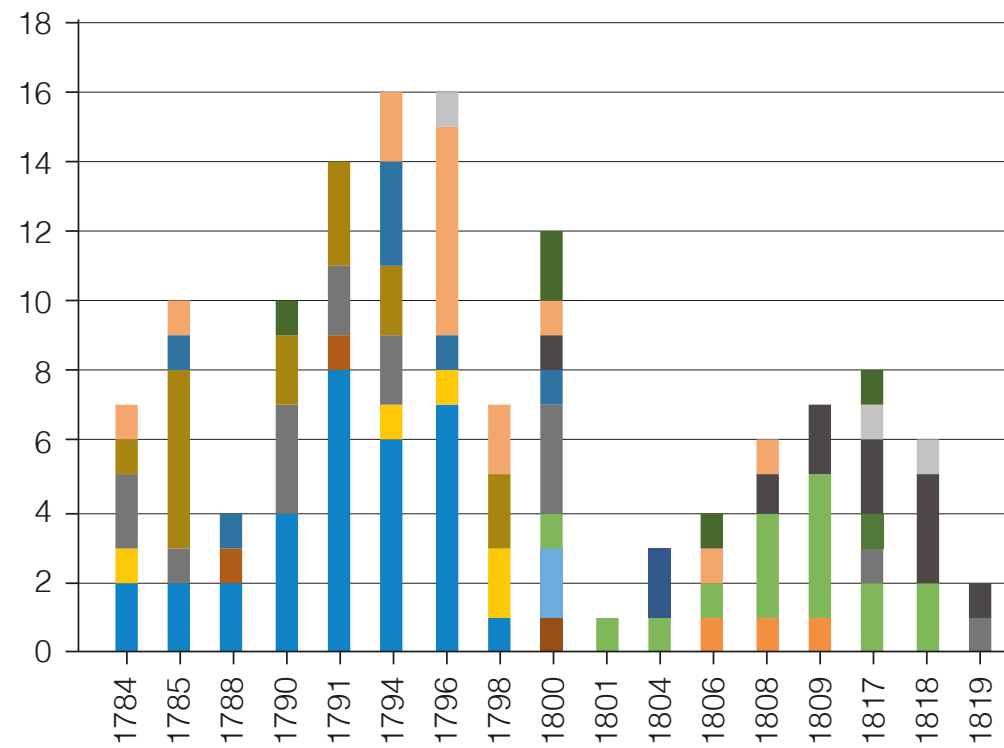

\section{$\leftrightarrow$ FIGURA 2.}

Procedencia de los registros realizados en Pamplona en I784-I8I9

Fuente: elaboración propia con base en AGN (C) 3, IO, 27, 3I, 57, 75, I77; (L).

7 reales. Esta diferencia de ingresos fue constante entre las alcabalas de las dos ciudades, de modo tal que Girón mantuvo un ingreso superior a 500 pesos entre 1785 y I8I7.

El bajo recaudo se debe a que la ciudad no era el punto de destino de los efectos importados, sino un lugar de paso de la mayoría de los bienes provenientes del golfo de Maracaibo; solamente entraba una pequeña cantidad de lo traído desde allí al consumo de la ciudad. Una muestra de I82 guías que se encontraron registradas entre 1789 y 1809 con destino al nororiente neogranadino revela que el $62 \%$ de los bienes introducidos durante esos años tuvo como principal destino la villa de San José de Cúcuta. Si a esta cantidad le sumamos las guías con destino a la Villa del Rosario (I7\%), y las que llevaban como destino "los valles de Cúcuta" (7\%), se aprecia que dicha región controló el $86 \%$ de las importaciones traídas desde el puerto venezolano.

Las guías con destino directo a la ciudad de Pamplona equivalían, por el contrario, al $7 \%$; si a ellas se suman los productos introducidos hacia Mérida, Barinas y San Cristóbal que fueron posteriormente remitidos a Pamplona, da un $\mathrm{I} 3 \%$ de las importaciones recibidas desde el puerto. Las mercancías llegadas al valle de Cúcuta eran redistribuidas hacia el interior del virreinato. 
La otra razón por la cual predominó el tráfico a través de Cúcuta, en lugar de la ciudad de Pamplona, fue la evasión fiscal que se presentaba al pasar los géneros por la villa. Entre la promulgación de la apertura de entrada de bienes y 1807 hubo varias irregularidades. En una carta enviada por el administrador de alcabalas, Juan Antonio Briceño, en I807, al virrey dice que a varias de las partidas ingresadas desde Maracaibo al interior del virreinato no se les cobraba debidamente lo requerido, porque estos bienes al llegar a puerto no se sabía si provenían de las colonias amigas o de España: "es difícil distinguir cuales se han venido de la península y cuáles de colonias, pues lo que ocurre allí al comprarlas compran indistintamente de donde proceden, ni los mismos de real hacienda de allí podrán asegurarlo" (AGN, $A$, I8, f. 30 r.).

Asimismo, en la respuesta dada a Briceño por las autoridades, se le especificó que no debía darle obstrucción a los bienes que simplemente iban de paso por Cúcuta y solo debían pagar los impuestos requeridos en su lugar de destino, que en la capital era del $2 \%$ a los bienes traídos de Cartagena o Maracaibo, por decisión del virrey (AGN, $A$, I8, f. 33 v.).

La alta fluctuación del ingreso de alcabalas de Pamplona, sobre todo en los años de I80I, I804 y I808 refleja un abastecimiento irregular de bienes que pudo ser ocasionado por las guerras atlánticas entre España y Gran Bretaña, lo que dificultaba la navegación a través del Caribe así como la entrada de navíos a los puertos (Assadourian y Palomeque 5). Estas tendencias decrecientes en el recaudo de efectos importados durante años específicos fueron comunes en las cajas de Honda, Tunja y Mompox, donde el año de i8or demostró un descenso en cada una de las regiones (Moreno 236). Sin embargo, el mismo año no demuestra un declive tan pronunciado en Santafé, sino que se mantiene a un precio relativamente similar al de $\mathrm{I} 8 \mathrm{OoO}$ (Moreno 22I). Esta tendencia muestra la amplia diferencia entre los mercados de Santafé y los de las provincias.

La alta oscilación de Pamplona evidencia un mercado no tan bien abastecido como Santafé y Tunja, y que era fácilmente afectado por los conflictos atlánticos. La proximidad al puerto venezolano y el depender, a partir de I800, exclusivamente de los géneros internados desde Maracaibo fueron factores que propiciaron la escasa cantidad de importaciones en la ciudad. Es igualmente 
probable que el comercio ilegal de mercancías supliera a Pamplona, como lo hizo a otras regiones del nororiente neogranadino (Bohórquez y Palacio 192)7.

Por último, el periodo entre i809 y i8I7 representa un vacío en las cuentas fiscales de la ciudad de Pamplona. La ausencia de los libros manuales, al igual que de cargo y data, e incluso los resúmenes generales durante el periodo de la independencia y de las Provincias Unidas de la Nueva Granada son una particularidad de las administraciones que se encontraban en el nororiente del recién creado país.

A pesar de estos vacíos, es posible observar que en los años posteriores a la reconquista, cuando la administración de alcabala volvió a funcionar de manera normal, el recaudo de géneros de Castilla disminuyó de manera significativa. El descenso de dicho ramo es directamente proporcional al descenso del cobro total de alcabala durante I8I7-I8I9.

El descenso de los efectos tasados en la ciudad de Pamplona se relaciona con el descenso general del comercio entre España y América después de i8io. Mientras en el periodo de 1806 a I809 hubo un crecimiento de las exportaciones de España a la Nueva Granada, los años posteriores se caracterizaron por una tendencia decreciente para las importaciones provenientes de la Península (Moreno, El comercio).

Las guerra de reconquista llevada a cabo por Pablo Morillo en su paso hacia el interior del virreinato había minado las arcas públicas y destinado la mayor cantidad del recaudo al sostenimiento del ejército, al igual que había instaurado el ramo de raciones para el mantenimiento de las fuerzas militares (Pinto 219). Lo poco recaudado en el ramo de efectos de Castilla durante el periodo de I8I7 a I8I9 fue en su mayoría destinado al reparo de la guerra y a cubrir la data que superaba el recaudo de la provincia, debido a los gastos correspondientes al reparo de bienes ocasionado por las tropas de Morillo; gran parte de estas tendieron a ser pagos y reparaciones a víctimas del periodo independentista y de reclamaciones previas a I8Io (AGN, $C$, I77).

7 Las redes de contrabando encontradas por Bohórquez y Palacio conectaban a las ciudades de Girón y San Gil con las de la provincia de Tunja. Existía así una red organizada a partir de las relaciones personales, por la cual corrían flujos de mercancías ingresadas de manera ilegal que buscaban sobreponerse a las restricciones impuestas por el Virreinato sobre el abastecimiento de los asentamientos del interior. 


\section{Origen y variedad de géneros importados por Maracaibo}

La importación de géneros a través de Maracaibo se articulaba al mercado interno neogranadino. El objetivo de las importaciones fue abastecer el interior del virreinato de artículos de lujo y herramientas para el desempeño de las labores mineras y agrícolas. El modo de producción colonial requería diferentes cadenas productivas que abastecieran los centros mineros de los géneros necesarios para el desarrollo de la actividad productiva, la cual funcionó en el espacio americano como un eje que arrastraba el resto de las actividades económicas para el desarrollo de la actividad minera (Assadourian 20).

Las redes de abastecimiento del mercado interno tendían a sobrepasar las barreras jurisdiccionales del virreinato, uniendo diferentes centros de producción y consumo. Un caso claro es la conexión entre la provincia de Popayán y la Audiencia de Quito, donde los textiles quiteños y los bienes importados desde Guayaquil alimentaban las necesidades de las diferentes zonas mineras payanesas (Torres, Entre el oro I3O-I3I).

Los géneros extranjeros no tuvieron un papel diferente en la economía neogranadina. Los efectos europeos cumplieron una doble función en el espacio americano. En primer lugar, a través de la introducción de herramientas y metales como hierro o acero podía abastecerse a las minas y fincas de los bienes necesarios para la continuación de las actividades productivas.

Por otro lado, las importaciones desempeñaron también un preponderante papel social. Las telas y los alimentos importados de Europa servían como un símbolo de estatus social, a la vez que abastecían principalmente una demanda de las clases altas que deseaban adquirir dichos bienes. El uso de telas importadas funcionó como un elemento de diferenciación social entre el pueblo llano y la casta española y criolla (Wilk 93)

Los géneros introducidos desde Maracaibo hacia la Nueva Granada dependieron en gran medida de un sistema de redes de comerciantes para circular de un espacio a otro. Son pocos los casos en que los efectos son introducidos directamente desde España. El $46 \%$ de las mercancías adquiridas a través de Maracaibo se originaba de compras hechas en las tiendas públicas de la ciudad portuaria. Las pulperías funcionaban en gran medida como intermediarios entre los navíos que descargaban y las personas interesadas en llevar las mercancías hacia el virreinato. 
Los interesados en internar los bienes solían tener contactos en las ciudades principales que servían de intermediarios para movilizar los bienes desde la costa venezolana. Don Andrés Montovio, para internar sus productos a la región, delegaba a Felipe Casanova, a fin de que este llevara los productos de Maracaibo a la villa de San José de Cúcuta; allí entregaría los bienes a don Pedro Marcino, que a su vez los remitiría al interior del virreinato (AGN, C, IO5).

El 2I \% de lo introducido al virreinato corresponde a efectos comprados directamente a embarcaciones ancladas en el puerto. Por otro lado, el I7 \% de los efectos provenía de diferentes puertos del Caribe. Aquí fueron predominantes tres tendencias: la entrada al puerto de navíos extranjeros, buques que zarparon desde Maracaibo bajo el pedido de algún comerciante con destino a las colonias neutrales y el comercio con otras posesiones del Imperio español, principalmente Cuba.

Mientras la primera era de navíos pertenecientes a comerciantes de Estados Unidos o Francia que entraban a vender sus mercancías al puerto, las otras dos fueron más complejas. El comercio con los diferentes puertos del Caribe implicó la posibilidad de crear contactos y redes sociales más allá de los límites regionales.

Algunos comerciantes contaban con el capital y los contactos necesarios para introducir desde diferentes puertos efectos de Castilla y llevarlos hasta el mercado neogranadino. Don Manuel José Álvarez, dueño de una goleta registrada en España, introdujo 526 pesos en géneros de Castilla en I807, los cuales fueron llevados a su nombre y en consignación a don Manuel Pérez a la villa de San José de Cúcuta (agn, $C$, IO5).

Así mismo, en el periodo de I790 a I8I9 don Andrés Montovio ordenó en varias ocasiones que se ingresaran ciertos bienes en específicos desde el comercio de las islas de Cuba y Santomas al virreinato, a través de la conexión con el puerto de Maracaibo (AGN, $C$, I4I).

Las conexiones sociales entre diferentes actores comerciales ubicados en diferentes partes del Imperio permitieron la facilidad de circulación de bienes europeos y americanos, haciendo que las acciones colectivas de los mercaderes provinciales se conectaran con actores que operaban en escalas mucho más grandes en el comercio atlántico. Estas conexiones regionales permitían la configuración de redes sociales espaciales de negociación (Ibarra IO20).

Mientras el comercio libre entre las posesiones españolas se facilitó gracias a la pertenencia al Imperio, el tráfico de bienes entre la Nueva Granada y los territorios no españoles en el Caribe fue bastante conflictivo. Si bien se permitía 
la entrada de navíos de otras naciones en los puertos de Cartagena, Santa Marta y Maracaibo, en ciertas ocasiones los funcionarios americanos pondrían trabas a las embarcaciones extranjeras. En I79I se generó una real orden que prohibía que a los puertos americanos arribaran mercancías finas como telas, relojes y cajas de tabaco con el símbolo de la Libertad Americana ${ }^{8}$, para evitar cualquier instigación a revueltas en contra de la Corona (AGN, MISC, 39, f. 943 r.).

En ocasiones, a los navíos que atracaban en los puertos de la Nueva Granada se les inspeccionaban la mercancía y se les indagaba para descartar cualquier clase de contrabando. En I809, un interrogatorio hecho al capitán de la goleta Elizabeth Picot, atracada en Santa Marta, procedente de Filadelfia y con destino a Maracaibo, surtió todo un proceso de requisa e indagación para verificar que no correspondiera a cargamentos de contrabando (AGN, $A D$, I5, f. 797 r.).

Los géneros introducidos desde el extranjero debían, a la hora de llegar al puerto, catalogarse e igualarse en valor a los bienes traídos de Espańa, a la vez que debían pagar los impuestos requeridos por la Corona. Una contraguía a nombre de don Salvador Saumell, del año I80o, cuyos efectos fueron introducidos desde diferentes puertos del Caribe, e iban a ser vendidos en las villas del Socorro y San Gil, demuestra este hecho.

Las importaciones realizadas por Saumell el I3 de septiembre de I80o, por un valor total de 5.078 pesos, fueron introducidas a través del puerto de Maracaibo a petición del comerciante, desde Cuba, Santa Marta y puertos de naciones neutrales, valiéndose para ello de la goleta Mariana Santa Clara. El cargamento traído al puerto contenía principalmente efectos extranjeros cuyo valor excedía a los bienes nacionales y a los efectos espańoles libres que venían con ellos.

Las 545 piezas de tela extranjera con un valor de 2.382 pesos superaban a los I.584 pesos de géneros nacionales y espańoles libres que llegaron con la carga? Además de pagar el derecho de avería, los bienes extranjeros vendidos en Maracaibo debían pagar un $5 \%$ de alcabala en la ciudad venezolana, mientras que los efectos nacionales solo el $3 \%$ (AGN, $C$, I4I).

El I2 \% de las guías no registraban su zona de procedencia. Aunque puede ser un error de los trabajadores del puerto, no hay que descartar la posibilidad

8 El símbolo de la libertad americana hace referencia a una inscripción que traían los bienes de Estados Unidos. Asimismo, la restricción existía para cualquier otro símbolo que hiciera alusión a la independencia de las colonias angloamericanas.

9 La contraguía presentada en la Villa del Rosario con los precios de los objetos reportados se encontraba valorada en reales de vellón, con una equivalencia de i peso $=$ is reales. 
de que hayan sido objetos de contrabando que al llegar a Maracaibo hubieran sido legalizados y recibido una guía provisional para su circulación (Moreno 22I). Existió igualmente un $9 \%$ que provenía de las otras provincias en el interior de Venezuela, principalmente Guyana y Caracas, que registraban su paso a través de Maracaibo y posteriormente a los valles de Cúcuta.

Como se presenta en la figura 3, la mayor cantidad de géneros importados fueron textiles. La apertura de los diferentes puertos de España durante el último cuarto del siglo xvin permitió la llegada de diversas clases de productos a las costas americanas. En las distintas guías se encuentran sarazas de Barcelona, hierro de Vizcaya y aceitunas de Andalucía. Las importaciones del puerto de Maracaibo registran una variedad de 336 tipos de telas diferentes, fabricadas tanto en algodón como seda, lana y cáñamo. La variedad de géneros producidos a fines del siglo Xvin y principios del xix es posible gracias a la entrada de géneros extranjeros a las colonias americanas y el desarrollo de la industria textil catalana.
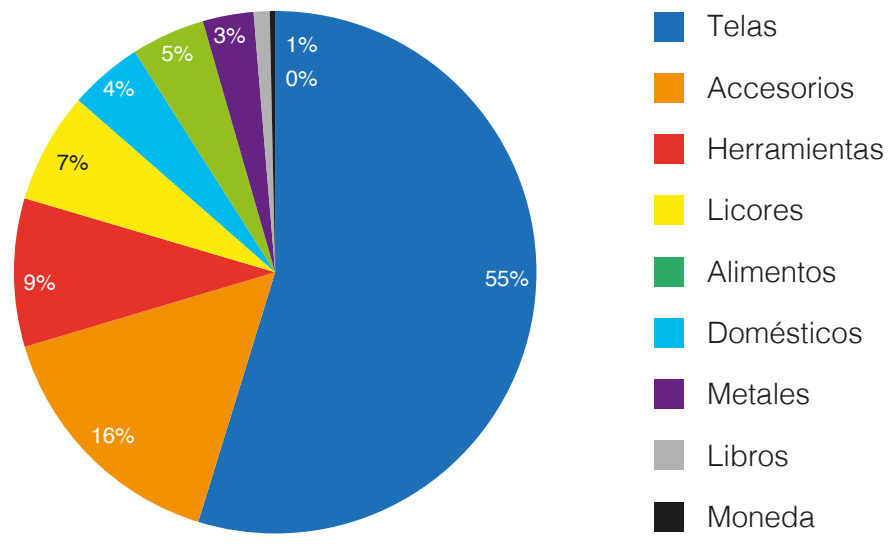

-r FIGURA 3.

Distribución de productos importados. Guías de Maracaibo de 1797, I803, 1807 y $1808^{\text {I0 }}$

Fuente: elaboración propia con base en AGN (C) 3, IO, 27, 3I, 57, 75, IO5, I4I y I77.

Io La figura 3 representa la distribución de productos registrados de una muestra equivalente a roo guías de comercio de los años 1797, 1803, 1807 y 1808. 
El flujo de mercancías americanas a la península ibérica, después de la creación del Reglamento de Libre Comercio, expandió la industria catalana y fortaleció el comercio a través del puerto de Barcelona. El algodón maltés y el americano, que arribaron a las costas de Cataluña, permitieron el desarrollo de una industria textil cuyo principal mercado eran las colonias americanas (Sánchez y Valls-Junyent 6I). En el periodo de 1785 a 1796 los lienzos y telas de algodón pintados correspondían al $27 \%$ de las exportaciones, seda el $17 \%$ y textiles de lana un I2 \% (Fisher, The Economic I47-I48).

Los 336 tipos de tela diferentes que se encontraban en los registros muestran tanto la variedad de sus orígenes como de los materiales en los cuales estaban fabricados. Podemos encontrar, fácilmente, desde prendas de algodón fabricadas en España, hasta olanes, bretañas y ruanes traídos de Francia y seda de Europa.

El segundo tipo de producto más importado fueron accesorios manufacturados. En esta categoría entran sombreros, zapatos, joyas y sobre todo pañuelos. Al menos la mitad de las importaciones de este tipo de productos se basaba en pañuelos de diferentes materiales y colores. Estos se relacionan a su vez con el desarrollo de la industria textil en España, que permitió la generación de una gran cantidad de bienes de este tipo.

En tercer lugar se encuentran las herramientas (9\%) y los licores (7\%). El origen de estos bienes tendía a ser la península ibérica. En su mayoría, la importación propendía a ser de machetes y hachas, mientras que los licores solían ser aguardiente de España y diferentes clases de vino. El I4\% restante solían ser productos de diversos tipos, bastante inusuales, y que pocas veces aparecen en las guías como alimentos imposibles de conseguir en la región, como fideos, aceitunas y almendras. Y también libros y acero.

A pesar de que las contraguías no especifican el destino de la totalidad de las mercancías, algunas de ellas muestran que los centros de consumo principales de estos géneros eran las ciudades de Santafé, Girón, la villa del Socorro y San Gil. La alta importación de textiles desde Maracaibo hacia la región nororiental de la Nueva Granada se relaciona con el alto consumo de telas extranjeras, como lo presentan Edwin Muñoz y James Torres. Una vez las mercancías importadas llegaban a esta región, con frecuencia se dispersaban a diferentes regiones del virreinato, a la vez que se intercambiaban por bienes de la tierra (Bohórquez y Palacio I80).

La región nororiental andina se caracterizó por ser un centro de producción agrícola y textil que a fines del siglo XviII se especializó en el abastecimiento de telas, principalmente de las regiones mineras antioqueñas (Twinam Iıз) y 
la capital, para su redistribución hacia las zonas del centro y sur del virreinato (Muñoz y Torres I89).

Ante esta especialización regional, es difícil establecer los motivos por los cuales las telas fueron la principal demanda de los centros de producción textil del virreinato. Es probable que la dependencia de las telas extranjeras que tuvo la República de Colombia en el siglo xix se hubiera comenzado a manifestar durante los últimos años del gobierno español en América, cuya industria artesanal acusó un pronunciado retroceso en las primeras décadas, debido a los altos costos de transporte de las mercancías (Johnson I24).

Por otro lado, es probable que la demanda corresponda a un cambio en los hábitos de cultura material de la población. La creciente demanda correspondió a la preponderancia de los objetos importados como una muestra de estatus, donde la suntuosidad de las posesiones demostraba una posición prominente en la sociedad (Jiménez 47).

Por último, la conexión entre Santafé y Maracaibo requiere un estudio propio. La investigación de James Torres sobre los flujos monetarios en la Nueva Granada ha mostrado la existencia de redes que conectaban el oro acuńado de la capital virreinal con la región marabina, transitando a través de Cúcuta y Pamplona, junto a una red que introducía plata desde Mérida y el puerto de Maracaibo hacia Santafé (Torres, Bullion 3I-34).

El flujo de dinero metálico con dirección a la provincia de Pamplona y los Andes venezolanos fue observado ante todo a través de la red de abastecimiento de cacao hacia Santafé (23). Quizá las importaciones de efectos de Castilla durante la primera mitad del siglo XVIII fortalecieran e incrementaran los flujos monetarios entre el interior y la región marabina.

\section{Conclusiones}

La investigación realizada es apenas una aproximación al comercio entre la Nueva Granada y el golfo de Maracaibo. Se ha podido observar cómo el comercio de bienes alcanzó su apogeo luego de I800 y cuan significativo fue para la región nororiental. El periodo posterior a I8Io registra un descenso en el comercio de bienes importados, debido a los constantes conflictos de la Corona y la independencia de la Nueva Granada.

El ingreso de Pablo Morillo y la restauración del orden monárquico en la Nueva Granada no afectó el comercio que, como lo demuestra la cantidad 
de bienes ingresados a Pamplona, disminuyó considerablemente. Este no era un hecho aislado, sino, como lo ha demostrado Edwin Muñoz, la alcabala de la capital demostró una reducción tanto de géneros de la tierra como de bienes importados.

La ciudad de Pamplona funcionó como un centro de redistribución de géneros importados en el nororiente de la Nueva Granada a fines del siglo XVIII, paralelo a otros centros ya existentes, como lo fue Mompox. Los géneros traídos desde Maracaibo remplazaron en su totalidad a los traídos desde Cartagena. Sin embargo, la red a través de la cual se movían los efectos importados solía ser, en ciertos casos específicos, la misma a través de la que los pamploneses negociaban cacao con la capital del virreinato. Futuras investigaciones deben centrarse en comprender cómo ambas redes funcionaron de forma paralela y cómo fueron afectadas por los eventos de i8io.

Con respecto a las guías, lo que se analizó es una simple fracción de un mercado mucho más amplio. El control de los valles de Cúcuta sobre los géneros importados desde Venezuela explica por qué los asentamientos de este lugar eran los que recaudaban la mayor alcabala del virreinato; sin embargo, la distribución al interior de la Nueva Granada sigue sin explicarse.

Debe investigarse, observando desde los centros de consumo, si los efectos llegados al interior de la Nueva Granada desde Maracaibo remplazaron progresivamente a los traídos desde Cartagena, como sucedió en el caso de Pamplona, o, por el contrario, fueron una sustitución en los momentos que no podían importar bienes desde el norte.

En el caso de la ciudad de Pamplona, vemos que las personas que tributan géneros traídos desde Cartagena rara vez lo hacen con productos de Maracaibo. Sin embargo, desconocemos si la misma dinámica funcionó en el interior del virreinato, sobre todo en la capital de Santafé.

Asimismo, la alta importación de telas extranjeras de principios del siglo XIX trae a colación preguntas relacionadas con la producción textil del virreinato. Si bien los textiles europeos no competían con los producidos en el Socorro y San Gil, por tener demanda en sectores diferentes de la sociedad, cabe indagar si el alto flujo de telas afectó los precios de las manufacturas locales.

Por último, las conexiones presentes en el puerto de Maracaibo muestran un dinamismo entre comerciantes de diferentes zonas del imperio y con agentes comerciales de naciones aliadas y neutrales a España. Ciertas mercancías solicitadas directamente desde Maracaibo a Cuba muestran que las redes sociales de estos actores podían salir de una escala provincial y participar directamente en 
el comercio atlántico. Dichas redes, al igual que Ibarra demostró en el caso de Guadalajara, pudieron ser mucho más significativas en la reorientación del mercado interno de la capitanía de Venezuela y del nororiente de la Nueva Granada.

Si bien en la investigación no se encontró ninguna conexión directa entre comerciantes de Pamplona y miembros del comercio de Cádiz, Cuba o Veracruz, las conexiones presentes entre vecinos de Maracaibo y los diferentes puertos españoles, tanto ibéricos como del Caribe, mostraron necesitar de los miembros del comercio regional del nororiente neogranadino para facilitar la circulación de bienes importados hacia el interior de la Nueva Granada. Es necesario revisar la extensión que poseían estas redes de comercio en el Caribe y analizar cómo y a través de qué medios se conectaban con las redes locales y provinciales que facilitaban el comercio en el interior de la Nueva Granada.

\section{\% \\ $\begin{array}{llllllllllll}\text { B I } & B & L & I & \mathbf{O} & G & \mathbf{R} & \mathbf{A} & \mathbf{F} & \mathbf{I} & \mathbf{A}\end{array}$}

\section{F U E N T ES PR I M A R I S}

\section{A. Archivo}

Archivo General de la Nación, Bogotá, Colombia (AGN).

Sección Colonia.

Administración de Alcabalas (A) 8, 18.

Aduanas (AD) is.

Miscelánea (MISC) 39.

Sección Archivo Anexo II

Administración de Alcabalas (AA) I3.

Real Hacienda Cuentas

Cajas (C) 3, I0, 27, 31, 57, 75, 105, I4I y 177.

Sección Archivo Anexo III

Real Hacienda Cuentas

Libros (L) I 432C, 2826C, 2830C, I536C, 2826C, I 488R, 2033 R.

Sección Mapas y Planos (MP)

Mapoteca 6, ref. 87 . 


\section{B. Impresos}

Caldas, Francisco, José. Semanario del Nuevo Reino de Granada, Bogotá: Editorial Minerva, 1942 .

\section{F U E N T ESSECUNDARIAS}

Assadourian, Carlos. El sistema de la economía colonial. Lima: IEP Ediciones, 1982.

Assadourian, Carlos y Silvia Palomeque. "Importaciones de productos de Castilla/europeos en Córdoba, I800-I8ı””. Andes, n. ${ }^{\circ}$ 12, 2001, pp. 1-21.

Bohórquez, Jesús y Gabriel Palacio. "La circulación y el consumo en las cuencas de los ríos Sogamoso y Lebrija: comerciantes y consumidores en el siglo XVIII”. Historia Crítica, n. ${ }^{\circ} 35,2008$, pp. 176-200. https://doi.org/10.7440/histcrit35.2008.10

Cardozo, Germán. "El circuito agroexportador marabino a mediados del siglo XIX”. Anuario de Historia Regional y de las Fronteras, n. 1, 1995, pp. 3-46.

De la Pedraja, René. "El comienzo de la crisis en el comercio colonial: la Nueva Granada 1796I80 I". Desarrollo y Sociedad, n. 2 , I979, pp. 21 I-229. https://doi.org/10.13043/dys.2.3

Ferreira, Carmen. "El crédito colonial en la provincia de Pamplona-Nueva Granada: uso de censo consignativo". Signos Históricos, n. ${ }^{\circ}$ I, 1999, pp. 59-83.

Fisher, John. Relaciones económicas entre España y América hasta la independencia. Madrid: Editorial Mapfre, 1992.

--.. The Economic Aspects of Spanish Imperialism in America, I492-I810. Liverpool: Liverpool University Press, 1997.

Guerrero Rincón, Amado Antonio. “Territorio, economía y sociedad. Desarrollo regional en la provincia de Pamplona, siglo Xviıı”. Tesis doctoral en Historia, Universidad Internacional de Andalucía, 2014.

Guerrero Rincón, Amado Antonio, Silvano Pabón y Carmen Ferreira. Los pueblos del cacao: origenes de los asentamientos urbanos en el oriente colombiano. Bucaramanga: Universidad Industrial de Santander, 1998.

Ibarra, Antonio. "Redes de circulación y redes de negociantes en Guadalajara colonial: mercado, élite colonial e instituciones". Historia Mexicana, vol. 56, n. ${ }^{\circ}$, 2007, pp. I0I7-I04I.

Imizcoz, José María. “Comunidad, red social y élites. Un análisis de la vertebración social en el Antiguo Régimen”. Elites, poder y red social. Las élites del País Vasco y Navarra en la edad moderna, editado por José María Imizcoz. Bilbao: Universidad del País Vasco, 1996, pp. 13-50. 
Jiménez Meneses, Orián. “Objetos y cultura. Rituales, flujos y elaboraciones en el Nuevo Reino de Granada”. Historia Crítica, n. ${ }^{\circ}$ 39, 2009, pp. 44-6r. https://doi.org/10.7440/ histcrit39.2009.04.

Johnson, David. Santander siglo XIX: cambios socioeconómicos. Bogotá: Carlos Valencia Editores, 1984 .

Mcfarlane, Anthony. "El comercio exterior del Virreinato de la Nueva Granada: conflictos en la política económica de los Borbones (1783-1789)”. Anuario Colombiano de Historia Socialy de la Cultura, n. ${ }^{\circ}$ 6-7, 1972, pp. 69-115.

Meisel Roca, Adolfo. "Crecimiento, mestizaje y presión fiscal en el virreinato de la Nueva Granada, 176I-I800”. Cuadernos de Historia Económica y Empresarial, n. ${ }^{\circ}$ 28, 201 , pp. I-91. https://doi.org/10.32468/chee.28

Moreno Rivera, Nathalie. "Circulación de efectos de Castilla en el virreinato de la Nueva Granada a finales del siglo XVIII". Fronteras de la Historia, vol. I8, n. ${ }^{\circ}$ I, 201 4, pp. 2 II-2 49. https://doi.org/I0.22380/202746885I

Moutoukias, Zacarias. "Negocios y redes sociales: modelo interpretativo a partir de un caso rioplatense (siglo XviII)". Caravelle. Cahiers du monde hispanique et luso-brésilien, n. ${ }^{\circ} 67$, 1996, pp. 37-55. https://doi.org/10.3406/carav.1996.2707

Muñoz Rodríguez, Edwin y James Torres Moreno. "La función de Santafé en los sistemas de intercambio en la Nueva Granada a fines del siglo Xviı". Fronteras de la Historia, vol. I8, n. ${ }^{\circ}$ I, 2014 , pp. I65-210. https://doi.org/I0.22380/2027468850

Pinto Bernal, José Joaquín. Entre Colonia y República: fiscalidad en Ecuador, Colombia y Venezuela, I780-1845. Bogotá: Instituto Colombiano de Antropología e Historia, 2018.

Sánchez, Alex y Francesc Valls-Junyent. "El mercado del algodón en Barcelona durante la crisis del Antiguo Régimen, 1790-1840”. Revista de Historia Industrial, n. ${ }^{\circ}$ 8, 2015, pp. 6I-93.

Torres, James. "Bullion and Monetary Flows in the Northern Andes: New Evidence and Insights, 1780-1800”. Tiempo \& Economia, vol. 6, n. I, 2019, pp. 13-46. https://doi. org/10.21789/24222704.1430

---. "Entre el oro y la plata: Quito, el suroccidente de la Nueva Granada y el movimiento de mercancías norandino a fines del siglo XviII". Colonial Latin American Review, vol. 27, n. ${ }^{\circ}$ I, 2018, pp. II 4-139. https://doi.org/10.1080/10609164.2018.1448540

Twinam, Ann. Mineros, comerciantes y labradores: las raices del espiritu empresarial en Antioquia; I763-I8ro. Medellín: Fondo Rotatorio de Publicaciones (FAES), i985.

Urdanet Arlene. "San José de Cúcuta, en el comercio marabino del siglo xix”. Boletín Americanista, n. 38,1998 , pp. $247-258$. 
Wilk, Richard. "A Taste of Home: The Cultural and Economic Significance of European Food Exports to the Colonies". Food and Globalization: Consumption, Markets and Politics in the Modern World, editado por Alexander Nützenadel y Frank Trentmann. Nueva York: Oxford, 2008, pp. 93-108. 


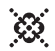

\section{A N E X O I . \\ $\mathbf{M} \mathbf{A} \mathbf{A}$}

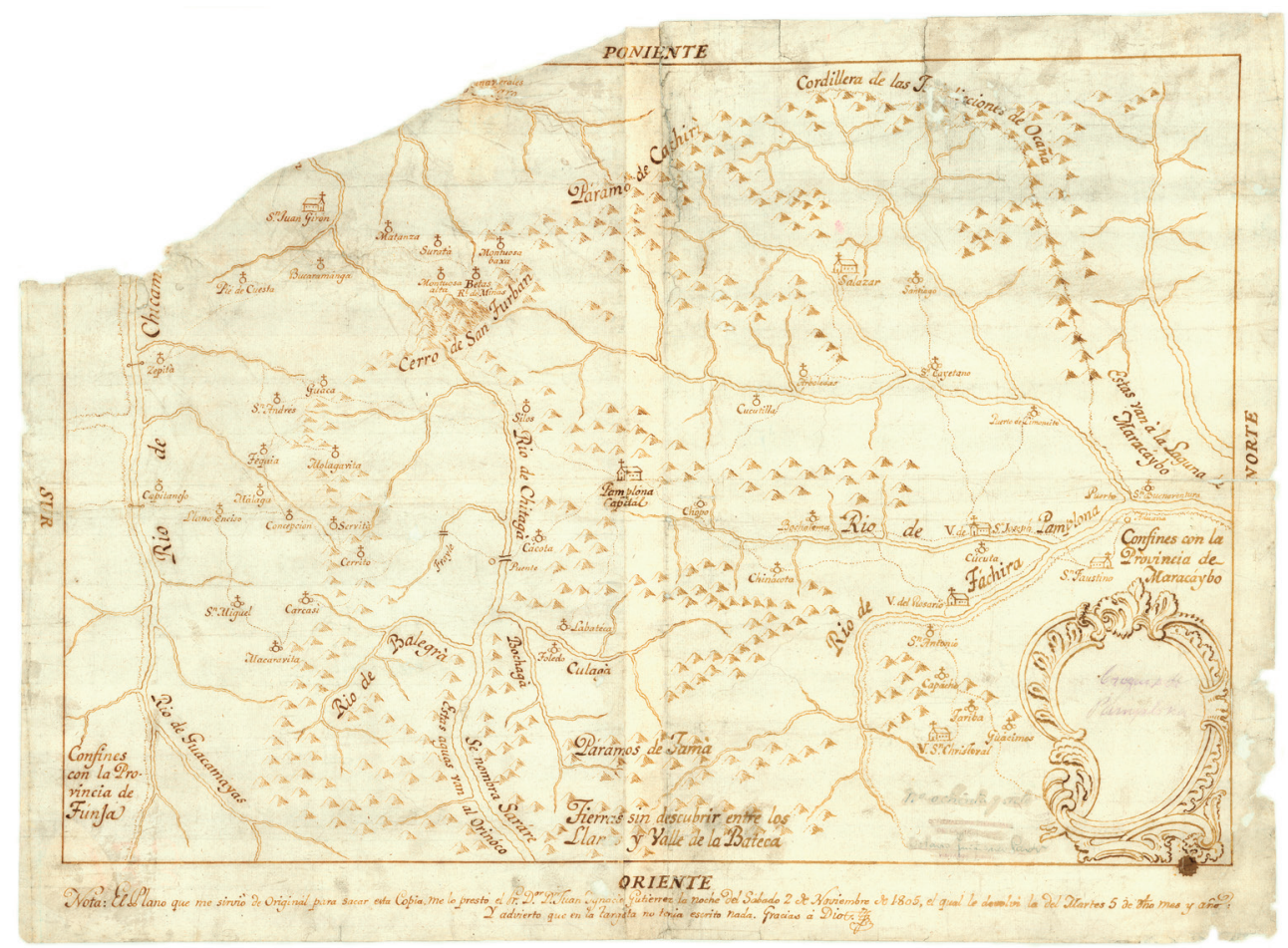

$\leftrightarrow$ FIGURA 4 .

Mapa de la provincia de Pamplona (I805)

Fuente: AGN, MP, 6, ref. 87. 


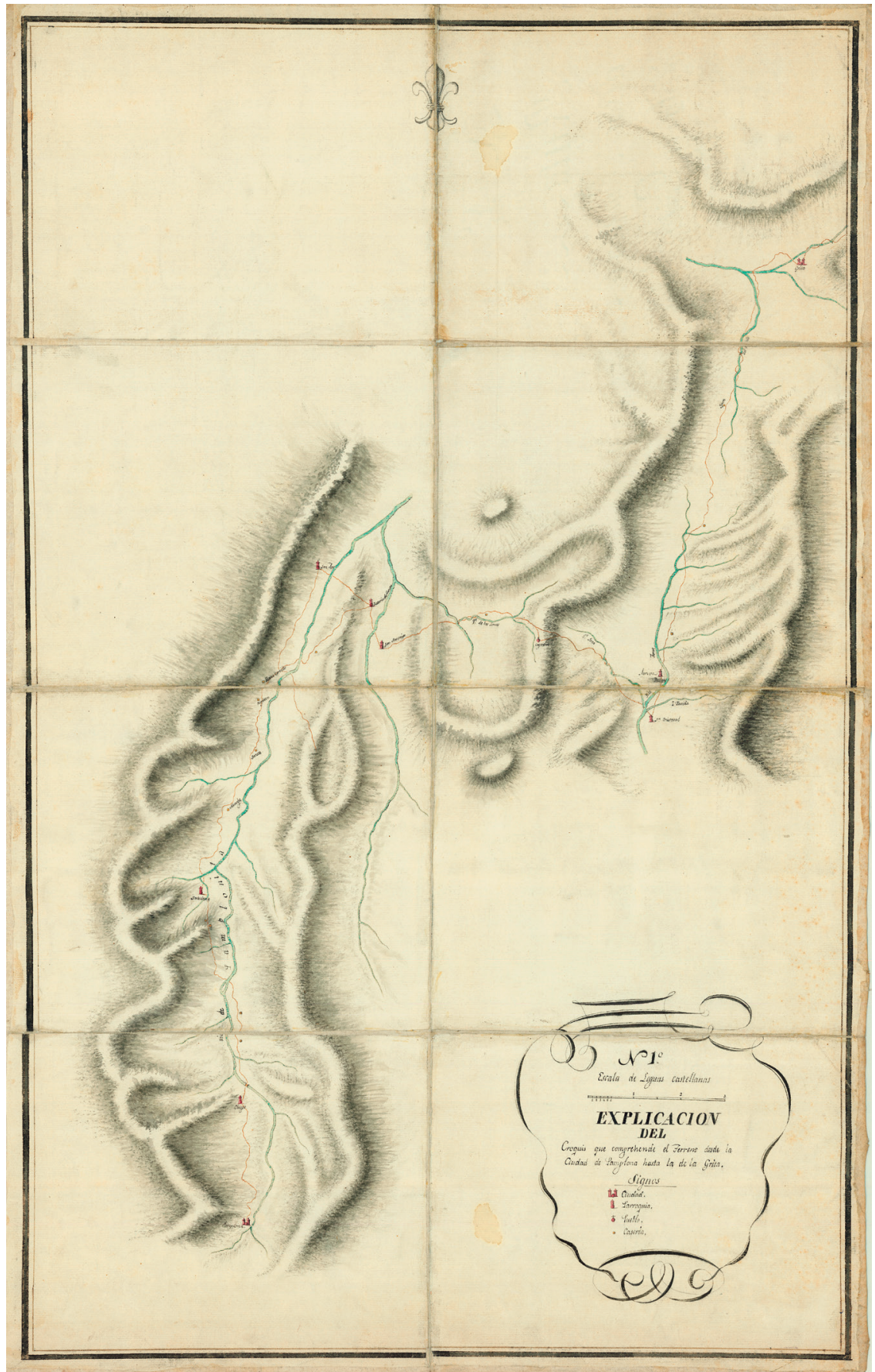

$\rightarrow$ FIGURA 5 .

Paso entre Pamplona y La Grita, Venezuela (I700)

Fuente: AGN, MP, 6, ref. 267. 